\title{
Article
}

\section{Effect of Chorionicity on Umbilical Cord Blood Acid-Base Analysis of the Second Twin}

\author{
Matthew J. Blitz ${ }^{1}$, Burton Rochelson ${ }^{1}$, Nontawan Benja-Athonsirikul2,3, Weiwei Shan ${ }^{2,3,4}$, Meir Greenberg ${ }^{5}$ and \\ Luis A. Bracero ${ }^{1}$ \\ ${ }^{1}$ Department of Obstetrics and Gynecology, Division of Maternal-Fetal Medicine, Southside Hospital, Donald and Barbara Zucker School of Medicine at \\ Hofstra/Northwell, Bay Shore, NY, USA, ${ }^{2}$ Department of Obstetrics and Gynecology, Division of Maternal-Fetal Medicine, North Shore University Hospital, Donald \\ and Barbara Zucker School of Medicine at Hofstra/Northwell, Manhasset, NY, USA, ${ }^{3}$ Department of Obstetrics and Gynecology, Donald and Barbara Zucker \\ School of Medicine at Hofstra/Northwell, New Hyde Park, NY, USA, ${ }^{4}$ Biostatistics Unit, Feinstein Institute for Medical Research, Manhasset, NY, USA and \\ ${ }^{5}$ Department of Obstetrics and Gynecology, Division of Medical Informatics, North Shore University Hospital, Donald and Barbara Zucker School of Medicine at \\ Hofstra/Northwell, Manhasset, NY, USA
}

\begin{abstract}
Our objective was to determine whether chorionicity affects umbilical cord blood acid-base parameters of the second twin. This was a retrospective cohort of twin pregnancies delivered at $\geq 23$ weeks of gestation at a tertiary hospital from 2010 to 2016 . Patients were included if arterial and venous umbilical cord gas results were available for both newborns and chorionicity was confirmed histologically. Exclusion criteria included intrauterine fetal demise of either twin prior to labor, major fetal anomalies, monoamnionicity, uncertain chronicity and twin-to-twin transfusion syndrome. The primary outcome evaluated was the umbilical artery (UA) pH of the second twin. A total of 593 dichorionic (DC) and 86 monochorionic (MC) twin pregnancies were included. No difference in UA pH was observed between MC and DC twins. Among vaginal deliveries $(n=97)$, the UA pH of the first twin was higher than the second twin $(7.26$ vs. 7.24 ; $p=.01$ ). Twin-to-twin delivery interval (TTDI) $\geq 20 \mathrm{~min}$ was associated with a higher UA $\mathrm{pH}$ in the first twin compared to the second twin (7.25 vs. 7.16, respectively; $p=.006$ ). Multivariable logistic regression was used to predict arterial $\mathrm{pH}<7.20$ for the second twin; the most predictive factors were arterial $\mathrm{pH}<7.20$ for the first twin, chronic hypertension and prolonged TTDI. Chorionicity was not associated with any acid-base parameter of umbilical cord blood in either the first or second twin. No differences in neonatal outcomes were observed based on chorionicity or birth order. Populations with a lower cesarean delivery rate may yield different findings.
\end{abstract}

Keywords: Twin pregnancy; chorionicity; umbilical cord; acid-base; placenta

(Received 11 December 2019; accepted 29 February 2020; First Published online 6 April 2020)

Compared to singleton pregnancies, twin pregnancies are at increased risk for adverse perinatal outcomes, including preterm delivery, fetal growth restriction, congenital anomalies, neonatal intensive care unit admission and fetal loss (Chauhan et al., 2010) It has also long been recognized that compared to first-born twins, second-born twins are at increased risk for morbidity and mortality independent of presentation, chorionicity or infant sex (Armson et al., 2006; Hartley \& Hitti, 2005). Such outcomes may be attributed to both antepartum and intrapartum events. As a result of a shared placental circulation, monochorionic (MC) gestations are at risk for additional complications compared to dichorionic (DC) gestations, including twin-to-twin transfusion syndrome (TTTS) and twin anemia polycythemia sequence (Hack et al., 2008). There is conflicting literature about whether chorionicity has intrapartum effects on acid-base physiology or neonatal outcomes of first- and second-born twins (Axelsdottir \& Ajne, 2018; Ehrenberg et al., 2004; Hjorto et al., 2014).

Author for correspondence: Matthew J. Blitz, Email: mblitz@northwell.edu Cite this article: Blitz MJ, Rochelson B, Benja-Athonsirikul N, Shan W, Greenberg M, and Bracero LA. (2020) Effect of Chorionicity on Umbilical Cord Blood Acid-Base Analysis of the Second Twin. Twin Research and Human Genetics 23: 178-183, https:// doi.org/10.1017/thg.2020.10
Umbilical cord blood that obtained promptly after delivery allows for determination of newborn acid-base status at birth. Arterial $\mathrm{pH}$ and base excess, in particular, are important measures of the condition of the neonate; abnormal values may indicate the occurrence of an acute intrapartum hypoxic event. The risk of neonatal morbidity is inversely related to arterial $\mathrm{pH}$ (i.e., highest risk at lowest $\mathrm{pH}$ ). In twin pregnancies, a prolonged twin-totwin delivery interval (TTDI) is associated with pathologic fetal acidemia and adverse neonatal outcomes in the second twin (Axelsdottir \& Ajne, 2018; Leung et al., 2004; Stein et al., 2008) The effect of other intrapartum and clinical factors, such as chorionicity, on the acid-base physiology of second-born twins is less certain; a review of the literature reveals conflicting results. Recently, one large study by Axelsdottir and Ajne (2018) concluded that chorionicity does not affect twin cord gas results. Others have speculated that the presence of placental vascular anastomoses in $\mathrm{MC}$ twin pregnancies would produce more concordant acid-base parameters than in DC twin pregnancies (Ehrenberg et al., 2004). Leung et al. (2004) concluded that there may be impairment of uteroplacental exchange after delivery of the first twin. If true, this finding may be more pronounced in MC compared to DC pregnancies due to the shared placental 
circulation. The impact of this, if any, may only be relevant when vaginal delivery is attempted, given the risk of additional exposure to intrauterine hypoxic events in the second twin.

Prior studies investigating acid-base physiology in twin pregnancies have often been limited by small sample sizes (Ehrenberg et al., 2004; Leung et al., 2004) with comparatively few MC compared to DC gestations (Hjorto et al., 2014), racially homogenous populations that may hinder generalizability (Axelsdottir \& Ajne, 2018), and scant neonatal outcome data. The aim of our study was to ascertain whether chorionicity affects the umbilical cord blood acid-base parameters of the second twin in a large, diverse population at a single tertiary referral hospital with detailed neonatal records. Our primary objective was to determine whether chorionicity is associated with acidosis of the second twin. Secondary objectives were to determine whether chorionicity affects arterial $\mathrm{pH}$ discordance or neonatal outcomes among twin-pairs.

\section{Materials and Methods}

This retrospective cohort study evaluated all women with twin gestations who delivered at greater than 23 weeks of gestational age at a single, tertiary, university medical center from January 1, 2010 to December 31, 2016. Patients were included if umbilical cord gas results (both arterial and venous) were available for both newborns, and histological evaluation of the placenta was performed after delivery to determine chorionicity. Exclusion criteria included intrauterine fetal demise of either twin prior to labor, major fetal anomalies, monoamniotic twins, uncertain chronicity and TTTS. The Northwell Health Human Research Protection Program and Institutional Review Board approved the study protocol. This research adhered to the STROBE checklist for observational studies (https://www.strobe-statement.org).

Medical records were reviewed to obtain baseline characteristics of the study population, including maternal age, gravidity, parity, race, body mass index, medical and surgical history, and obstetrical and gynecological history. For each patient, the antepartum course and obstetrical outcomes were reviewed, and the following data were collected: chorionicity, gestational age at delivery, mode of delivery, indication for primary cesarean, newborn birth weights, Apgar scores, TTDI and pregnancy complications. Neonatal complications were identified, including neonatal intensive care unit (NICU) admission, neonatal death, respiratory distress syndrome, sepsis, intraventricular hemorrhage, blood transfusion, hyperbilirubinemia and others. Chorionicity was confirmed by placental histology evaluation after delivery. All data were stored in a secure REDCap database.

At our institution, umbilical cord blood (both arterial and venous) is routinely collected for the assessment of fetal oxygenation after all live births greater than 23 weeks of gestational age unless an insufficient quantity $(<0.5 \mathrm{ml})$ is obtained. Cord clamping is typically performed within $90 \mathrm{~s}$ of birth, and sampling and laboratory analysis is performed within $60 \mathrm{~min}$ of birth. Arterial and venous $\mathrm{pH}, \mathrm{pCO}_{2}, \mathrm{PO}_{2}, \mathrm{HCO}_{3}$ and base excess are reported.

The primary outcome was the umbilical artery (UA) $\mathrm{pH}$ of the second twin (evaluated as a continuous variable). Threshold values of arterial $\mathrm{pH}<7.00$ and $<7.20$ were evaluated (as binary variables). Secondary outcomes included NICU admissions and neonatal outcomes and complications.

For patient demographics, mean and standard deviations were reported for continuous clinical variables and frequency for categorical variables. When clinical variables were compared between groups of patients (e.g., between DC and MC), $t$ test or the Wilcoxon rank-sum test were used to compare continuous variables contingent on the normality of the variable distribution. Chi-square and Fisher's exact test were used to compare the distribution of categorical variables between groups. Statistical significance was defined as $p<.05$. A multivariable logistic regression was carried out to examine the association between UA $\mathrm{pH}<7.20$ in the second-born twin and the following potential explanatory variables: chorionicity, maternal age, multiparity, chronic hypertension, diabetes, hypertensive disorders or pregnancy, assisted reproductive technology (ART), gestational age at delivery, TTDI, cesarean delivery for NRFHT, cesarean delivery for baby B only, 1- or 5-min Apgar score $<7$ for baby A and UA $\mathrm{pH}<7.2$ for baby A. Significant predictors were selected using the stepwise Akaike information criterion (AIC) method. Odds ratios and corresponding $95 \%$ confidence intervals are presented. Analyses were generated with RStudio Desktop 1.1.463 (RStudio Inc., Boston, MA, USA) using R 3.5.1 (R Foundation for Statistical Computing, Vienna, Austria) (R Core Team, 2013) and/or SAS Studio 3.8 Enterprise Edition build on SAS 9.04 (SAS Institute Inc, Cary, NC, USA).

\section{Results}

During the study period, a total of 1277 twin pregnancies delivered at $\geq 23$ weeks of gestational age and were evaluated for inclusion. After applying exclusion criteria, 679 twin pregnancies (593 DC; 86 $\mathrm{MC})$ remained for analysis. The study population had a mean maternal age of $33.8 \pm 5.3$ years and was approximately $70 \%$ Caucasian (Table 1). Patients in the DC group were older and more likely to have had a pregnancy resulting from ART compared to the MC group. There was no difference in race, prepregnancy BMI, gestational or pregestational diabetes, or hypertensive disorders of pregnancy between groups. As would be expected based on current recommendations from the American College of Obstetrics and Gynecology (ACOG), MC pregnancies delivered at earlier gestational ages than DC pregnancies (35.6 vs. 36.1 weeks) and were more likely to result in preterm birth $(70.9 \%$ vs. $49.6 \%$; ACOG, 2019). The rate of cesarean delivery was high in both groups, but even more so in the DC group.

No differences in umbilical cord blood gas parameters were observed between MC and DC twins for either the first or second twin (Table 2). UA pH $<7.20$ was seen in $13 \%(n=88)$ of second twins compared to $11 \%(n=76)$ of first twins $(p=.32)$. UA $\mathrm{pH}<7.00$ was seen in only four first twins and four second twins $(0.6 \%)$. Among vaginally delivered twins $(n=97)$, the UA pH of the first twin was higher than the second twin (7.26 vs. 7.24; $p=.01)$. In addition, among deliveries in which the first twin delivered vaginally and the TTDI was $\geq 20 \mathrm{~min}$, the first twin had a significantly higher UA pH than the second twin ( 7.25 vs. 7.16 respectively; $p=.006$ ). MC first twins were more likely than DC first twins to be admitted to the NICU (55.8\% vs. $43.8 \%$, $p=.03$ ); no difference was found between MC and DC second twins.

Overall, MC twins were more likely to be admitted to the NICU than DC twins ( $55.8 \%$ vs. $44.5 \%$ respectively; $p=.005$ ), a finding likely attributable to the increased incidence of preterm delivery in MC compared to DC twins. However, regardless of chorionicity, second twins did not have an increased rate of neonatal complications or NICU admissions compared to first twins (Table 3).

In the final multivariable logistic regression model to predict arterial $\mathrm{pH}<7.20$ for the second twin, multiple statistically 
Table 1. Maternal demographics and obstetrical outcomes of monochorionic and dichorionic twin pregnancies included in study population

\begin{tabular}{|c|c|c|c|}
\hline Characteristic & $\begin{array}{l}\text { Monochorionic } \\
\quad(n=86)\end{array}$ & $\begin{array}{l}\text { Dichorionic } \\
\quad(n=593)\end{array}$ & $p$-Value \\
\hline Maternal age (years) & $32.0 \pm 5.5$ & $34.0 \pm 5.3$ & .003 \\
\hline$\geq 35$ & $30(34.9)$ & $253(42.7)$ & .17 \\
\hline \multicolumn{4}{|l|}{ Race $^{a}$} \\
\hline Caucasian & $35(72.9)$ & $246(69.3)$ & .61 \\
\hline Other & $13(27.1)$ & $109(30.7)$ & \\
\hline BMI prepregnancy ${ }^{\mathrm{b}}\left(\mathrm{kg} / \mathrm{m}^{2}\right)$ & $25.0 \pm 6.3$ & $26.2 \pm 6.1$ & .15 \\
\hline$\geq 30$ Group & $13(17.6)$ & $101(21.4)$ & .45 \\
\hline Gestational weightgain $^{\mathrm{c}}(\mathrm{lb})$ & $39.2 \pm 14.5$ & $38.9 \pm 14.8$ & .87 \\
\hline Exceeds IOM guidelines $^{d}$ & $15(21.7)$ & $92(19.6)$ & .68 \\
\hline \multicolumn{4}{|l|}{ Parity } \\
\hline Nulliparous & $38(44.2)$ & $329(55.4)$ & .05 \\
\hline Multiparous & $48(55.8)$ & $264(44.5)$ & \\
\hline Pregnancy resulting from ART & $13(15.1)$ & $284(47.9)$ & .0001 \\
\hline \multicolumn{4}{|l|}{ Medical history } \\
\hline Diabetes & $2(2.3)$ & $7(1.2)$ & .39 \\
\hline Hypertension & $1(1.2)$ & $12(2.0)$ & .59 \\
\hline \multicolumn{4}{|l|}{ Pregnancy complications } \\
\hline Gestational diabetes & $9(10.5)$ & $65(11.0)$ & .89 \\
\hline Gestational hypertension & $4(4.7)$ & $25(4.2)$ & .85 \\
\hline $\begin{array}{l}\text { Preeclampsia or HELLP } \\
\text { syndrome }\end{array}$ & $9(10.5)$ & $82(13.8)$ & .39 \\
\hline $\begin{array}{l}\text { Gestational age at delivery } \\
\text { (weeks) }\end{array}$ & $35.6 \pm 2.2$ & $36.1 \pm 2.5$ & .04 \\
\hline$<37$ & $61(70.9)$ & $294(49.6)$ & .002 \\
\hline$<34$ & $14(16.3)$ & $94(15.9)$ & .92 \\
\hline \multicolumn{4}{|l|}{ Mode of delivery ${ }^{\mathrm{e}}$} \\
\hline Vaginal & $19(22.1)$ & $78(13.2)$ & .04 \\
\hline Cesarean & $67(77.9)$ & $515(86.8)$ & \\
\hline \multicolumn{4}{|l|}{ Indication for primary cesarean } \\
\hline $\begin{array}{l}\text { Breech or other } \\
\text { malpresentation }\end{array}$ & $11(22.4)$ & $128(32.0)$ & .48 \\
\hline Dystocia & $1(2.0)$ & $8(2.0)$ & \\
\hline Elective & $25(51.0)$ & $176(44.0)$ & \\
\hline Nonreassuring fetal status & $7(14.3)$ & $35(8.8)$ & \\
\hline Other & $5(10.2)$ & $53(13.3)$ & \\
\hline Delivery interval ${ }^{f}(\mathrm{~min})$ & $5 \pm 2.7$ & $14 \pm 15.6$ & .0001 \\
\hline
\end{tabular}

Note: BMI, body mass index; HELLP, hemolysis, elevated liver enzymes, low platelet count; IOM, Institute of Medicine; ART, assisted reproductive technology. Data are $n(\%)$ and mean \pm standard deviation unless otherwise specified. Bold values denote statistical significance at $p<.05$.

aRace data available for $59.4 \%$ of population $(n=403)$.

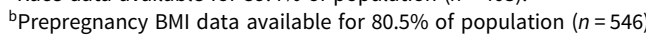

'Gestational weight gain data available for $79.2 \%$ of population $(n=538)$.

${ }^{\mathrm{d}}$ For twin pregnancy, the IOM recommends a gestational weight gain of 37-54 lb for women of normal weight, 31-50 lb for overweight women and 25-42 lb for obese women.

${ }^{e}$ Combined vaginal cesarean performed for four dichorionic and zero monochorionic pregnancies.

${ }^{f}$ After vaginal delivery of twin $\mathrm{A}$ ( $n=19$ monochorionic, $n=82$ dichorionic).

significant factors were identified (Table 4). However, the low odds ratios (i.e., <2) for most variables indicate that their effects are likely small. The stepwise AIC method was used to select
Table 2. Neonatal outcomes and umbilical cord blood gas results of monochorionic and dichorionic twin pregnancies

\begin{tabular}{|c|c|c|c|}
\hline Characteristic & $\begin{array}{l}\text { Monochorionic } \\
\qquad(n=86)\end{array}$ & $\begin{array}{l}\text { Dichorionic } \\
\quad(n=593)\end{array}$ & $p$-Value \\
\hline \multicolumn{4}{|l|}{ Twin A } \\
\hline Birth weight (g) & $2363 \pm 484$ & $2445 \pm 555$ & .15 \\
\hline 1-min Apgar score $\leq 7$ & $13(15.1)$ & $69(11.6)$ & .36 \\
\hline 5-min Apgar score $\leq 7$ & $2(2.3)$ & $14(2.4)$ & .98 \\
\hline Arterial pH & $7.26 \pm 0.07$ & $7.26 \pm 0.06$ & .69 \\
\hline$<7.0$ & $1(1.2)$ & $3(0.5)$ & .47 \\
\hline$<7.2$ & $9(10.5)$ & $67(11.3)$ & .82 \\
\hline Arterial $\mathrm{pCO}_{2}(\mathrm{mmol} / \mathrm{l})$ & $54.5 \pm 8.0$ & $55.0 \pm 8.4$ & .56 \\
\hline Arterial $\mathrm{pO}_{2}(\mathrm{mmol} / \mathrm{l})$ & $20.5 \pm 6.0$ & $19.4 \pm 8.2$ & .13 \\
\hline Arterial $\mathrm{HCO}_{3}(\mathrm{mmol} / \mathrm{l})$ & $23.5 \pm 2.2$ & $23.6 \pm 2.3$ & .69 \\
\hline $\begin{array}{l}\text { Arterial base excess } \\
(\mathrm{mmol} / \mathrm{l})\end{array}$ & $-4.1 \pm 3.1$ & $-4.1 \pm 2.9$ & .96 \\
\hline$<-12$ & $4(4.7)$ & $16(2.7)$ & .32 \\
\hline Venous $\mathrm{pH}$ & $7.32 \pm 0.06$ & $7.32 \pm 0.06$ & .95 \\
\hline Venous $\mathrm{pCO}_{2}(\mathrm{mmol} / \mathrm{l})$ & $45.5 \pm 6.9$ & $46.1 \pm 7.3$ & .42 \\
\hline Venous $\mathrm{pO}_{2}(\mathrm{mmol} / \mathrm{l})$ & $59.1 \pm 18.9$ & $56.5 \pm 18.5$ & .25 \\
\hline Venous $\mathrm{HCO}_{3}(\mathrm{mmol} / \mathrm{l})$ & $22.5 \pm 2.1$ & $22.8 \pm 1.9$ & .20 \\
\hline $\begin{array}{l}\text { Venous base excess } \\
(\mathrm{mmol} / \mathrm{l})\end{array}$ & $-3.5 \pm 2.8$ & $-3.2 \pm 2.3$ & .41 \\
\hline
\end{tabular}

\begin{tabular}{|c|c|c|c|}
\hline Birth weight (g) & $2300 \pm 547$ & $2407 \pm 556$ & .09 \\
\hline 1-min Apgar score $\leq 7$ & $14(16.3)$ & $106(17.9)$ & .72 \\
\hline 5-min Apgar score $\leq 7$ & $6(7.0)$ & $25(4.2)$ & .26 \\
\hline Arterial $\mathrm{pH}$ & $7.25 \pm 0.07$ & $7.25 \pm 0.07$ & .77 \\
\hline$<7.0$ & $0(0)$ & $4(0.7)$ & - \\
\hline$<7.2$ & $8(9.3)$ & $80(13.5)$ & .28 \\
\hline Arterial $\mathrm{pCO}_{2}(\mathrm{mmol} / \mathrm{l})$ & $56.3 \pm 8.4$ & $56.0 \pm 8.4$ & .74 \\
\hline Arterial $\mathrm{pO}_{2}(\mathrm{mmol} / \mathrm{l})$ & $18.8 \pm 13.2$ & $17.5 \pm 9.6$ & .35 \\
\hline Arterial $\mathrm{HCO}_{3}(\mathrm{mmol} / \mathrm{l})$ & $23.9 \pm 2.1$ & $23.8 \pm 2.2$ & .67 \\
\hline $\begin{array}{l}\text { Arterial base excess } \\
(\mathrm{mmol} / \mathrm{l})\end{array}$ & $-3.9 \pm 2.9$ & $-4.0 \pm 3.1$ & .83 \\
\hline$<-12$ & $3(3.5)$ & $17(2.9)$ & .75 \\
\hline Venous $\mathrm{pH}$ & $7.31 \pm 0.07$ & $7.31 \pm 0.06$ & .78 \\
\hline Venous $\mathrm{pCO}_{2}(\mathrm{mmol} / \mathrm{l})$ & $47.4 \pm 7.5$ & $47.6 \pm 7.6$ & .83 \\
\hline Venous $\mathrm{pO}_{2}(\mathrm{mmol} / \mathrm{l})$ & $49.4 \pm 18.6$ & $48.3 \pm 19.9$ & .62 \\
\hline Venous $\mathrm{HCO}_{3}(\mathrm{mmol} / \mathrm{l})$ & $22.9 \pm 2.2$ & $23.1 \pm 1.9$ & .49 \\
\hline $\begin{array}{l}\text { Venous base excess } \\
(\mathrm{mmol} / \mathrm{l})\end{array}$ & $-3.3 \pm 2.9$ & $-3.2 \pm 2.5$ & .63 \\
\hline
\end{tabular}

Note: Data are $n(\%)$ and mean \pm standard deviation unless otherwise specified.

significant predictors from the full model with all potential explanatory variables (described above); the selected parameters in the final model included chronic hypertension, ART, TTDI, first twin birth weight, second twin birth weight and first twin arterial $\mathrm{pH}<7.20$. Chorionicity was not selected by the algorithm but it was added to the model because of its clinical importance rather than its statistical significance. In cases where arterial $\mathrm{pH}$ 
Table 3. Neonatal complications of newborn twins admitted to the neonatal intensive care unit (NICU) by chorionicity

\begin{tabular}{|c|c|c|c|}
\hline Characteristic & Monochorionic $(n=86)$ & Dichorionic $(n=593)$ & $p$-Value \\
\hline \multicolumn{4}{|l|}{ Twin A } \\
\hline NICU admission & $48(55.8)$ & $260(43.8)$ & .03 \\
\hline Length of stay (days) & $10.4 \pm 10.6$ & $14.0 \pm 17.4$ & .05 \\
\hline Gestational age at delivery (weeks) & $34.4 \pm 2.3$ & $34.3 \pm 2.6$ & .70 \\
\hline Birth weight (g) & $2110 \pm 463$ & $2066 \pm 519$ & .55 \\
\hline Any major neonatal complication & $24(50.0)$ & $137(52.7)$ & .73 \\
\hline Neonatal death & $1(1.2)$ & $1(0.2)$ & .43 \\
\hline Respiratory distress syndrome & $10(11.6)$ & $52(8.8)$ & .89 \\
\hline Sepsis & $3(3.5)$ & $19(3.2)$ & .79 \\
\hline Intraventricular hemorrhage & $2(2.3)$ & $21(3.5)$ & .35 \\
\hline Blood transfusion & $2(2.3)$ & $14(2.4)$ & .73 \\
\hline Hyperbilirubinemia & $22(25.6)$ & $131(22.1)$ & .56 \\
\hline Other adverse outcome & $0(0)$ & $5(0.8)$ & - \\
\hline \multicolumn{4}{|l|}{ Twin B } \\
\hline NICU admission & $48(55.8)$ & $268(45.2)$ & .07 \\
\hline Length of stay (days) & $12.4 \pm 13.1$ & $14.4 \pm 16.7$ & .36 \\
\hline Gestational age at delivery (weeks) & $34.4 \pm 2.3$ & $34.2 \pm 2.5$ & .64 \\
\hline Birth weight (g) & $2020 \pm 524$ & $2007 \pm 487$ & .85 \\
\hline Any major neonatal complication & $25(52.1)$ & $150(56.0)$ & .62 \\
\hline Neonatal death & $1(2.1)$ & $1(0.4)$ & .22 \\
\hline Respiratory distress syndrome & $11(22.9)$ & $61(22.8)$ & .98 \\
\hline Sepsis & $2(4.2)$ & $20(7.5)$ & .42 \\
\hline Intraventricular hemorrhage & $2(4.2)$ & $22(8.2)$ & .34 \\
\hline Blood transfusion & $4(8.3)$ & $17(6.3)$ & .61 \\
\hline Hyperbilirubinemia & $21(43.8)$ & $147(54.9)$ & .16 \\
\hline Other adverse outcome & $3(6.3)$ & $3(1.1)$ & .03 \\
\hline
\end{tabular}

Note: Data are $n(\%)$ and mean \pm standard deviation unless otherwise specified. Bold values denote statistical significance at $p<.05$.

Table 4. Results of multivariable logistic regression model to predict umbilical artery $\mathrm{pH}<7.20$ in the second-born twin

\begin{tabular}{lcll}
\hline Characteristic & Odds ratio & $95 \% \mathrm{Cl}$ & $p$-Value \\
\hline Monochorionicity & 1.31 & $0.59,2.76$ & .49 \\
\hline Chronic hypertension & 5.78 & $1.38,20.48$ & .009 \\
\hline Pregnancy resulting from ART & 1.68 & $1.00,2.83$ & .051 \\
\hline Twin-to-twin delivery interval & 1.09 & $1.05,1.14$ & .0001 \\
\hline Twin A birth weight & 1.00 & $1.00,1.00$ & .005 \\
\hline Twin B birth weight & 1.00 & $1.00,1.00$ & .015 \\
\hline Twin A arterial pH $<7.20$ & 14.37 & $8.48,24.76$ & .0001 \\
\hline
\end{tabular}

Note: ART, assisted reproductive technology. Bold values denote statistical significance at $p<.05$.

was less than 7.20 for the first twin, the second twin was 14 times more likely to have an arterial $\mathrm{pH}$ less than 7.20 , provided that all other variables in the model remain constant. In addition, when the mother had a diagnosis of chronic hypertension, the second twin was nearly six times more likely to have an arterial
$\mathrm{pH}<7.20$, again, when all other predictors are held constant. The effect of TTDI was muted in this model by the high prevalence of cesarean section. Although the birth weight of each twin was statistically significant, this effect may be statistical artifact given the odds ratio of approximately 1 and extremely narrow 95\% confidence intervals for both.

\section{Discussion}

In our study population, chorionicity was not associated with any acid-base parameter of umbilical cord blood in either the first or second twin. Furthermore, no differences in neonatal outcomes were observed based on chorionicity or birth order. Neither ACOG nor the Society for Maternal-Fetal Medicine currently recommends any altered intrapartum management based on chorionicity. Our findings are reassuring and provide more support for a single intrapartum management protocol for twin pregnancies, despite different recommendations regarding delivery timing based on chorionicity.

Previous studies have not adequately evaluated the contribution of maternal comorbidities to the arterial $\mathrm{pH}$ of the second twin. In singleton pregnancies, it is well established that maternal perfusion 
of the placenta is reduced with hypertensive disorders (Kovo et al., 2017). We observed that chronic hypertension was strongly associated with twin $\mathrm{B}$ arterial $\mathrm{pH}$ less than 7.20. In addition, when twin A arterial pH was less than 7.20 , twin B was much more likely to have an arterial $\mathrm{pH}$ of less than 7.20 as well. Thus, even in DC twin pregnancies, in which there are two separate placentas, fetal hypoxia is not independent from one twin to the other. We also confirmed previous reports that among vaginally delivered twins, $\mathrm{UA} \mathrm{pH}$ is on average lower in second twins compared to first-born twins (McGrail \& Bryant, 2005; Suh et al., 2007). Prolonged TTDI, herein defined as greater than $20 \mathrm{~min}$, was associated with a significantly decreased UA pH in the second twin, consistent with prior studies (Hartley \& Hitti, 2005; Stein et al., 2008). Of note, most of our study population was delivered by cesarean section $(>80 \%)$, which functionally eliminates prolonged TTDI. Other studies of umbilical cord $\mathrm{pH}$ in twin gestations have typically focused exclusively on vaginal deliveries (Axelsdottir \& Ajne, 2018; Hjorto et al., 2014; Leung et al., 2004) or populations in which vaginal deliveries comprised approximately half of cases (Ehrenberg et al., 2004; Schneuber et al., 2011; Usta et al., 2002; Young et al., 1985). MC pregnancies had a significantly shorter TTDI than DC pregnancies (after vaginal delivery of twin A); this finding has been demonstrated in other studies but not adequately explained (Axelsdottir \& Ajne, 2018; Hoffmann et al., 2012).

It must be acknowledged that fetal blood gas analysis has inherent limitations. A UA pH less than 7.00 is often used as a threshold to define pathologic fetal acidemia but this value alone does not indicate whether the primary cause is a fetal, placental or maternal disorder. Moreover, in a normal fetus with normal placental function, acute acidosis in labor is only rarely associated with adverse outcomes. Thus, the consequences of acidosis depend on the condition of the fetus before the insult and the severity and duration of acidosis (acute vs. chronic). In twin gestations, as noted above, the most consistently identified factor contributing to acidosis of the second twin is the TTDI.

Our study has several strengths. We evaluated a large sample of twin pregnancies at a single institution with detailed documentation of maternal medical history, peripartum management and neonatal outcomes. Although the population was approximately two-thirds of Caucasian, this represents considerably greater racial diversity than similar previous studies (Axelsdottir \& Ajne, 2018; Hjorto et al., 2014). In order to eliminate the possibility of arterial-venous mismatch that may erroneously suggest a higher $\mathrm{pH}$, deliveries were only included if paired arterial and venous cord gases were obtained for both twins (Westgate et al., 1994); previous large studies did not employ such rigorous inclusion criteria (Axelsdottir \& Ajne, 2018; Hjorto et al., 2014). There are also several limitations associated with our study. The design is retrospective. A relatively high cesarean delivery rate hinders generalizability of our findings to other clinical settings in which twin vaginal delivery is more common. We were unable to sufficiently evaluate predictive factors associated with $\mathrm{UA} \mathrm{pH}<7.00$ in the second twin due to the small number of cases $(n=4)$. Finally, this study only evaluated short-term clinical outcomes from the neonatal hospitalization and did not evaluate long-term neurodevelopment.

In summary, no significant differences in umbilical cord blood gas analysis and neonatal outcomes were observed in this large contemporary cohort of MC and DC diamniotic twin pregnancies. Therefore, intrapartum clinical management should not be affected by chorionicity. It is possible that populations with a lower cesarean delivery rate and concomitant prolongation of the TTDI may yield different findings. It should be emphasized that reduction in TTDI is not of sufficient benefit to justify planned cesarean section. ACOG recommends that women with diamniotic twin gestations whose presenting fetus is in a vertex position should be considered as candidates for a vaginal birth because no reduction in fetal or neonatal morbidity or mortality has been demonstrated with planned cesarean delivery (Barrett et al., 2013; Committee on Practice Bulletins - Obstetrics, Society for Maternal-Fetal Medicine, 2016). Further investigation is necessary to determine whether chorionicity independently affects $\mathrm{UA} \mathrm{pH}$ in certain subgroups of twin pregnancies, including those affected by fetal growth restriction, abnormal UA Doppler studies and maternal comorbidities.

Acknowledgments. Results of this study were presented at the Society for Reproductive Investigation 65th Annual Scientific Meeting in San Diego, California in March 2018. We thank Michael Qiu and Shreya Sanghani of the Business Intelligence Competency Center of Northwell Health and Shonah Sandel of the Division of Neonatal-Perinatal Medicine at Cohen Children's Medical Center of New York for their assistance with data retrieval. We also thank Stephanie Augustine, RNC for administrative support.

Financial Support. This research received no specific grant from any funding agency, commercial or not-for-profit sectors.

\section{Conflict of Interest. None.}

Ethical Standards. The authors assert that all procedures contributing to this work comply with the ethical standards of the relevant national and institutional committees on human experimentation and with the Helsinki Declaration of 1975, as revised in 2008.

\section{References}

American College of Obstetrics and Gynecology (ACOG). (2019). Opinion No. 764: Medically indicated late-preterm and early-term deliveries. Obstetrics \& Gynecology, 133, e151-e155.

Armson, B. A., O'Connell, C., Persad, V., Joseph, K. S., Young, D. C., \& Baskett, T. F. (2006). Determinants of perinatal mortality and serious neonatal morbidity in the second twin. Obstetrics \& Gynecology, 108, 556-564.

Axelsdottir, I., \& Ajne, G. (2018). Short-term outcome of the second twin during vaginal delivery is dependent on delivery time interval but not chorionicity. Journal of Obstetrics and Gynaecology, 39, 308-312.

Barrett, J. F., Hannah, M. E., Hutton, E. K., Willan, A. R., Allen, A. C., Armson, B. A., Twin Birth Study Collaborative Group. (2013). A randomized trial of planned cesarean or vaginal delivery for twin pregnancy. New England Journal of Medicine, 369, 1295-1305.

Chauhan, S. P., Scardo, J. A., Hayes, E., Abuhamad, A. Z., \& Berghella, V. (2010). Twins: prevalence, problems, and preterm births. American Journal of Obstetrics and Gynecology, 203, 305-315.

Committee on Practice Bulletins - Obstetrics, Society for Maternal-Fetal Medicine. (2016). Practice Bulletin No. 169: Multifetal gestations: Twin, triplet, and higher-order multifetal pregnancies. Obstetrics \& Gynecology, 128, e131-146.

Ehrenberg, H. M., Fischer, R. L., Westover, T., \& Mercer, B. M. (2004). The impact of chorionicity on umbilical cord acid-base values in twin gestations. Journal of Maternal-Fetal and Neonatal Medicine, 15, 307-312.

Hack, K. E., Derks, J. B., Elias, S. G., Franx, A., Roos, E. J., Voerman, S. K., Visser, G. H. (2008). Increased perinatal mortality and morbidity in monochorionic versus dichorionic twin pregnancies: Clinical implications of a large Dutch cohort study. BJOG, 115, 58-67.

Hartley, R. S., \& Hitti, J. (2005). Birth order and delivery interval: Analysis of twin pair perinatal outcomes. Journal of Maternal-Fetal and Neonatal Medicine, 17, 375-380.

Hjorto, S., Nickelsen, C., Petersen, J., \& Secher, N. J. (2014). The effect of chorionicity and twin-to-twin delivery time interval on short-term outcome 
of the second twin. Journal of Maternal-Fetal and Neonatal Medicine, 27, $42-47$.

Hoffmann, E., Oldenburg, A., Rode, L., Tabor, A., Rasmussen, S., \& Skibsted, L. (2012). Twin births: Cesarean section or vaginal delivery? Acta Obstetricia et Gynecologica Scandinavica, 91, 463-469.

Kovo, M., Bar, J., Schreiber, L., \& Shargorodsky, M. (2017). The relationship between hypertensive disorders in pregnancy and placental maternal and fetal vascular circulation. Journal of the American Society of Hypertension, $11,724-729$.

Leung, T. Y., Lok, I. H., Tam, W. H., Leung, T. N., \& Lau, T. K. (2004). Deterioration in cord blood gas status during the second stage of labour is more rapid in the second twin than in the first twin. BJOG, 111, 546-549.

McGrail, C. D., \& Bryant, D. R. (2005). Intertwin time interval: How it affects the immediate neonatal outcome of the second twin. American Journal of Obstetrics and Gynecology, 192, 1420-1422.

Schneuber, S., Magnet, E., Haas, J., Giuliani, A., Freidl, T., Lang, U., \& Bjelic-Radisic, V. (2011). Twin-to-twin delivery time: Neonatal outcome of the second twin. Twin Research and Human Genetics, 14, 573-579.
Stein, W., Misselwitz, B., \& Schmidt, S. (2008). Twin-to-twin delivery time interval: influencing factors and effect on short-term outcome of the second twin. Acta Obstetricia et Gynecologica Scandinavica, 87, 346-353.

Suh, Y. H., Park, K. H., Hong, J. S., Yoon, B. H., Shim, S. S., Park, J. S., Syn, H. C. (2007). Relationship between twin-to-twin delivery interval and umbilical artery acid-base status in the second twin. Journal of Korean Medical Science, 22, 248-253.

Usta, I. M., Nassar, A. H., Awwad, J. T., Nakad, T. I., Khalil, A. M., \& Karam, K. S. (2002). Comparison of the perinatal morbidity and mortality of the presenting twin and its co-twin. Journal of Perinatology, 22, 391-396.

Westgate, J., Garibaldi, J. M., \& Greene, K. R. (1994). Umbilical cord blood gas analysis at delivery: A time for quality data. British Journal of Obstetrics and Gynaecology, 101, 1054-1063.

Young, B. K., Suidan, J., Antoine, C., Silverman, F., Lustig, I., \& Wasserman, J. (1985). Differences in twins: the importance of birth order. American Journal of Obstetrics and Gynecology, 151, 915-921. 